\title{
Prediction of CPI in Saudi Arabia: Holt's Linear Trend Approach
}

\author{
Anis Ali $^{1} \&$ Ayman Mahgoub ${ }^{1}$ \\ ${ }^{1}$ Department of Management, College of Business Administration, Prince Sattam Bin Abdulaziz University, Al kharj, \\ Saudi Arabia \\ Correspondence: Anis Ali, Department of Management, College of Business Administration, Prince Sattam Bin \\ Abdulaziz University, Al kharj-11942, Saudi Arabia. E-mail: ah.ali@psau.edu.sa
}

Received: November 10, 2020

Accepted: December 16, 2020

Online Published: December 20, 2020

doi:10.5430/rwe.v11n6p302

URL: https://doi.org/10.5430/rwe.v11n6p302

\begin{abstract}
The Consumer Price Index (CPI) indicates and measures price level changes in an economy based on total purchased goods and services. CPI is calculated by dividing the cost of the market basket in a given year by the cost of the market basket in a Base Year and multiplied by 100. CPI is subject to the Classification of Individual Consumption by Purpose (COICOP) in Saudi Arabia. Home expenditure items, such as housing, water, electricity, gas, and other fuels, food, and beverages are considered high while weight, health, education, recreation, and culture are given low weight in the COICOP in Saudi Arabia. Holt's linear model based on three equations and popularly known as double exponential smoothing or linear exponential model and the most commonly used method in forecasting data based on internal trends. Holt's linear model is composed of three equations relating to smoothing, trend, and forecast. In this paper, the CPI data were taken monthly from the General Authority for Statistics, Saudi Arabia for the period from May 2019 to July 2020 with 15 realizations. The CPI for Saudi Arabia is predicted for the next twelve months and as observed from the trend of CPI, the prices of total purchased goods will increase in the next eleven months.
\end{abstract}

Keywords: Holt's linear model, CPI, Saudi Arabia, market basket, linear exponential model, expenditure groups

\section{Introduction}

The Consumer Price Index (CPI) measures the changes in the aggregate price level in an economy, which comprises the goods and services purchased by the consumer, generally. The CPI also measures the purchasing power changes of the currency of a nation and the price level of commonly purchased goods and services. The CPI measures the changes in the current year's prices comparing with the previous year's prices. Normally, CPI is calculated monthly or quarterly. Mathematically, CPI is calculated by dividing the cost of the market basket in a given year by the cost of the market basket in Base Year to get the CPI in the percentage of the outcomes multiplied by 100. The consumer price index is subject to the Classification of Individual Consumption by Purpose (COICOP) in Saudi Arabia. The relative weights of the expenditure groups or the weights to the divisions of basket price items commonly purchased items calculated total expenditure on the items during the household expenditure and income survey period dividing by the total general expenditure of all items during the household expenditure and income survey period.

Table 1. Relative weight for each division for the calculation of CPI in Saudi Arabia

\begin{tabular}{rlc}
\hline No. & Expenditure groups (2013) & Weight (\%) \\
\hline 1 & Food and Beverages & 18.87 \\
\hline 2 & Tobacco & 0.68 \\
\hline 3 & Clothing and Footwear & 6.23 \\
\hline 4 & Housing, Water, Electricity, Gas, and Other fuels & 25.38 \\
\hline 5 & Household Furnishings and Equipment & 8.56 \\
\hline 6 & Health & 2.35 \\
\hline 7 & Transportation & 9.95 \\
\hline 8 & Communication & 8.49 \\
\hline
\end{tabular}




\begin{tabular}{rlc}
\hline 9 & Recreation and Culture & 3.43 \\
\hline 10 & Education & 4.23 \\
\hline 11 & Restaurants and Hotels & 6.07 \\
\hline 12 & Miscellaneous Goods and Services & 5.76 \\
\hline General Index & 100 \\
\hline
\end{tabular}

Source: Design, consumer price index methodology, Gstat, Saudi Arabia, 2013

Table 1 explains that commonly purchased commodities are classified among the 12 divisions according to the General authority of Statistics of Saudi Arabia. In the calculation of CPI in Saudi Arabia, Housing, Water, Electricity, Gas, and Other fuels; Food and Beverages; Transportation; Household Furnishings and Equipment; and communication division's weights are more the others cost of baskets while Tobacco; Health; Recreation and Culture; and Education division's weights are lower than the other division. The CPI measures the inflation of the economy while inflation is the indicator of loss of the ability of the buying power of the currency. A regular increase in the CPI indicates the growth of the economy while the deviating growth in the CPI is alarming and reveals that the inhabitants of an economy are not able to buy basic goods and services. The prediction or forecasting of the CPI is necessary for the government, tax authorities, business organizations, and various institutions for policy formulation to face the near future challenges and sustain the economic growth of the economy. Holt's linear model is also known as the double exponential smoothing model or linear exponential smoothing. Holt's two-parameter model is known as double exponential smoothing or linear exponential model and the most common method used in forecasting data based on-trend. Holt's model is the composition of the three different equations to get the final result. The first equation is the smoothing equation and the second equation develops the trend while the third equation develops the final forecasted values. The results of Holt's linear forecasting model provide better results than the other models of prediction (Zhuet al, 2019). In the Saudi Arabian context, there is no study available applying Holt's method in predicting the CPI in Saudi Arabia. So, there is a need to apply Holt's linear trend model to forecast the most accurate CPI applying the cost of the market basket of commonly purchased goods and services of Saudi Arabia.

\section{Literature Review}

\subsection{Prediction of CPI Without Holt's Linear Trend Approach or Double Exponential Smoothing}

Akhter (2013) and Zhang et al. (2013) constructed a model ARMA (autoregressive moving average) and SARIMA (Seasonal Autoregressive Integrated Moving Average) and applied it to forecast the CPI accurately, respectively. Kharimah et al. (2015); Norbert et al. (2016); and Mustapa et al. (2019, June) found the ARIMA as the best model for forecasting the CPI and increasing prices. Jere et al. (2019) found Multicointegration a more accurate prediction model compared to the ARIMA $(3,1,3)$ in forecasting CPI in Zambia. Ahmar et al. (2018, June) applied the ARIMA (p.d,q) method to forecast CPI data in Indonesia using R software and found ARIMA $(1,0,0)$ is more accurate in the prediction of CPI.

\subsection{Prediction of CPI by Holt's Linear Trend Approach or Double Exponential Smoothing}

Ahmad \& Nor (2020) compared Holt's-Linear Trend and Holt's- Winters method in long-term forecasting and found the lowest error in Holt's- Winters method. Xing et al. (2020) explained that double exponential smoothing can be used as a suitable tool for landslide displacement trends while the hybrid model provides more accuracy. Syahrani \& Astuti (2020, April) carried a study and explored that forecasting enhances the capacity of infrastructure and improves the quality of services. They used the double and triple exponential method of forecasting and found that the double exponential method is comparative more accurate than the triple exponential method of forecasting. Tamber \& Oladejo (2020) used the Holt-Winters Additive Model in forecasting passengers' traffic of 23 airports with 75,879,653 passengers between 2003 to 2011 and forecasted the number of passengers from 2012 to 2019. Liu \& Wu (2020) applied a hybrid model Holt's exponential smoothing and whale optimization algorithm and found that the hybrid model provides accurate forecasting involving smaller calculations. Tratar \& Strmčnik (2016) conducted a study of heat load forecasting and found that Multiple Regression is suitable for short term forecasting while Holt-Winter's model for long term forecasting. Soni \& Srikanth (2017, May) used genetic programming and Holt-Winter's exponential smoothing method in inventory forecasting. Yang et al. (2017, April) conducted a study to predict aircraft failure rate to take an appropriate decision against aviation maintenance. They used the seasonal time series data using Holt-Winters exponential smoothing methods and found that the results are more accurate to predict 
the aircraft failure rate. Jere \& Siyanga (2016) forecasted the Inflation Rate of Zambia applying Holt's model and Auto-Regressive Integrated Moving Average (ARIMA) putting the monthly consumer price index from May 2010 to 2014. The results Support that the ARIMA $((12), 1,0)$ is the appropriate model for forecasting the CPI. But, ARIMA requires particular software while Holt's model gives similar results and can be calculated easily without any specific software. Mladenović et al. (2016) applied the Holt-Winters and ARIMA model for modeling and forecasting the monthly export trends of Serbia for 2015 and found the appropriateness of both methods. Karmaker et al. (2017) predicted jute yarn demand in Bangladesh and applied eight techniques of forecasting and found that the Holt-Winters additive model gives a better forecast with lower error determinants.

\subsection{Other Models Better Than the Holt-Winters Model}

Riofrio-Valarezo et al. (2020) carried out a comparative study of classical models like SARIMA and exponential smoothing and found that the Ecuadorian CPI forecasting model is appropriate than others. Ahmar et al. (2018) observed that $\alpha$-Sutte Indicator can be applied in the forecasting of finance, insurance, and time-series data with Additive Holt-Winters, Multiplicative Holt-Winters, and Automatic Time Series Forecasting and found more accurate than other models of prediction. Razali et al. (2017) carried a study to forecast the water consumption expenditure of Malaysian University by applying Holt- winters and ARIMA model and found that ARIMA $(2,1,4)$ model's results are better than the Holt-winters model. Şahinli, M. A. (2020) conducted one study on price forecasting of potato using Holt-Winters and ARIMA Methods and found that the ARIMA model is more appropriate that Holt's- Winters model according to mean absolute percentage error (MAPE), the root mean square error (RMSE) and the mean absolute deviation (MAD).

\subsection{Holt-Winters Model Better Than Other Models of Prediction}

Bujang et al. (2009) carried out a study of comparison between simple linear regression and model and Holt's linear trend model to predict the number of deaths in Malaysia and found that Holt's linear trend model is suitable in the prediction of the number of deaths in Malaysia. Tirkeş et al. (2017) studied demand forecasting using the Holt-Winters, trend analysis, and decomposition models and found that the results of the Holt-Winters and Decomposition models are better than the trend analysis. Zhu et al. (2019) forecasted spring onion seed demand applying hybrid Holt's- Winters and support Vector Machine model and found that the hybrid Holt's- Winters is more appropriate in forecasting the demand of the seed varieties, growing annual demand and constant annual demand than support Vector Machine. Saputra et al. (2016, October) predicted the crude oil price in Indonesia applying the Brown's and Holt's double exponential smoothing models and found that both models are feasible for prediction while the Double Exponential model Smoothing (DES) of Brown found the best as per MAPE and feasibility studies. Vijayakumar \&Vennila (2016) carried out a study of forecasting the reservoir inflow using the ARMA Model \& Holt-Winters Exponential Smoothening model and found that the exponential smoothing model's forecasted values and computed values are more appropriate than the ARMA model.

\section{Materials and Methods}

\subsection{Data of Consumer Price Index}

The CPI data of the Kingdom of Saudi Arabia was collected from the website of the General Authority for Statistics (Gstat), Saudi Arabia. The CPI data were taken monthly for the period from May 2019 to July 2020 with 15 realizations. The average value for Saudi Arabia during that period was 98.68 index points and the standard deviation is 0.40 with a minimum of 97.50 index points in May 2019 and a maximum of 104.00 index points in July 2020. The series of CPI has a positive trend for the predicted period. The MS- Excel 2010 and E-view 10 software was used to build the prediction model.

\subsection{Holt's Linear Trend Method}

If the time series contains a general trend, then a simple exponential smoothing is inappropriate, because its predictions lag behind the true level of the series. If the trend is positive, then the forecast of the simple exponential smoothing is usually very low and if the trend is negative, its forecast is usually very high. The Holt method corrects the problem by estimating both the current level of the series and the current rate of a trend growth or decline at each period. Predictions are realized (by Holt method) through trend mapping Estimated using the current level as a starting point (Chatfield, 2000). Holt's two-parameter model is a common model for smoothing and prediction based on-trend. Holt's model contains three separate equations that work together to generate a final prediction of the values. The first and second equation sets the last smoothed value of the trend of the past period and then trend updated over time, where the trend is expressed as the difference between the last two smoothed values, respectively. Finally, the third equation is used to generate the final prediction. Holt's model uses two parameters, one for level 
and the other for the trend. This method is also known as double exponential smoothing or trend-enhanced exponential smoothing (Box et al., 2011).

Forecasting equation for $\mathrm{w}$ periods:

$$
F_{t+w}{ }_{t}=V_{t}+w R_{t}
$$

Level equation:

$$
V_{t}=\alpha Z_{t}+(1-\alpha)\left(V_{t-1}-R_{t-1}\right)
$$

Trend equation:

$$
R_{t}=\beta\left(V_{t}-V_{t-1}\right)+(1-\beta) R_{t-1}
$$

where:

$Z_{t}$ denotes the series of interest

$V_{t}$ an estimate of the level of the series at time t.

an estimate of the trend of the series at time t. $R_{t}$

is the smoothing parameter for the level, $0 \leq \alpha \leq 1 \alpha$

is the smoothing parameter for the trend, $0 \leq \beta \leq 1 \beta$

Measuring Forecast Errors3.

To select the best model, we used some measurements to measures the accuracy of the model. In this paper three measurement accuracy determinants are used: Mean Absolute Error (MAE), the Mean Square Error (MSE), and the Root of Mean Square Error (RMSE). The mathematical formula used to calculate the above-stated errors are:

$$
\begin{aligned}
M A E & =\frac{\sum|e|}{n} \\
M S E & =\frac{\sum e^{2}}{n-1} \\
R M S E & =\sqrt{\frac{\sum e^{2}}{n-1}}
\end{aligned}
$$

Where $e$ is the estimated random error (residuals) is the difference between actual data and predicted, $n$ is the specified number of periods.

\section{Analysis, Results and Discussion}

One of the double exponential smoothing models has been identified, which is the two-parameter Holt model based on the time series data develops a trend and predicts future values. 


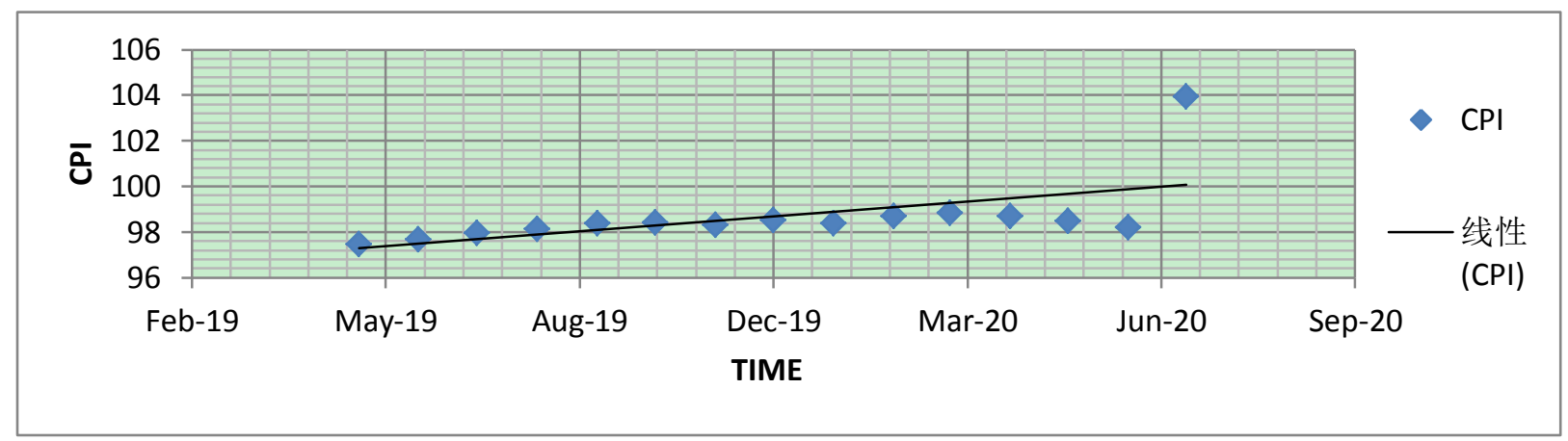

Figure 1. Scatter plot of CPI of Saudi Arabia

Originating Source: Based on data of CPI of Saudi Arabia available at https://www.stats.gov.sa/en/394

Figuring out from Figure 1 is that the time series does not have seasonality, but it has a general trend of increasing, i.e. a positive general trend of increasing CPI.

Holt developed a simple exponential smoothing extension to allow the prediction of trend data. This method includes one expectation equation and two smoothing equations (one for level and another one for the trend). The parameter for the level smoothing is denoted by $\alpha$ and the parameter for the trend smoothing is denoted by $\beta$.

Table 2. Double exponential smoothing model parameters

\begin{tabular}{lllrrrr}
\hline Model & & Estimate & \multicolumn{1}{l}{ SE } & \multicolumn{1}{c}{ S } & \multicolumn{2}{l}{ Sig. } \\
\hline CPI-Model_1 & \multirow{2}{*}{ No Transformation } & $\alpha$ (Level) & 0.10 & .161 & 5.321 & .000 \\
\cline { 3 - 8 } & & $\beta$ (Trend) & 0.60 & .209 & 3.653 & .001 \\
\hline
\end{tabular}

Originating Source: authors' own calculation based on data available at https://www.stats.gov.sa/en/394

From Table 2 it becomes clear that the best values of the level and the trends are 0.10 for level and 0.60 for trend and they are all significant at a significant level of 0.05 .

There are several criteria by which it is possible to compare the methods used to predict time series. The higher measures have a lower value and indicate that the predicted values coincide with the actual values. The most important of these measures used in this paper is the measure of Mean Absolute Errors (MAE), the Mean Squared Errors (MSE), and the Root Mean Squares of Errors (RMSE).

Table 3. Comparison of several models according to the measures of accuracy

\begin{tabular}{rrrrr}
\hline $\begin{array}{c}\text { Value of smoothing } \\
\text { constant } \alpha \text { (level) }\end{array}$ & $\begin{array}{c}\text { Smoothing constant } \beta \\
\text { (Trend) }\end{array}$ & RMSE & MSE & MAE \\
\hline 0.10 & 0.6 & 1.365608 & 1.864886 & 0.694761 \\
\hline 0.10 & 0.7 & 1.367595 & 1.870317 & 0.69628 \\
\hline 0.10 & 0.8 & 1.374887 & 1.890315 & 0.706056 \\
\hline 0.10 & 0.9 & 1.385817 & 1.920488 & 0.711941 \\
\hline 0.20 & 0.6 & 1.451559 & 2.107024 & 0.677187 \\
\hline 0.20 & 0.7 & 1.470704 & 2.162969 & 0.679644 \\
\hline 0.20 & 0.8 & 1.488042 & 2.21427 & 0.675685 \\
\hline 0.20 & 0.9 & 1.502471 & 2.257419 & 0.666881 \\
\hline 0.30 & 0.6 & 1.500789 & 2.252369 & 0.633399 \\
\hline & & & &
\end{tabular}




\begin{tabular}{rrrrr}
\hline 0.30 & 0.7 & 1.511297 & 2.284019 & 0.628271 \\
\hline 0.30 & 0.8 & 1.5177 & 2.303412 & 0.630787 \\
\hline 0.30 & 0.9 & 1.520874 & 2.313056 & 0.634268
\end{tabular}

Originating Source: authors' own calculation based on data available at https://www.stats.gov.sa/en/394

By comparing the different models with each other in table 3, it becomes clear that the best model is the model that has the lowest values of the different measures of accuracy used, which are: MAE, MSE, and RMSE. This model is a model that has values of 0.1 for level and 0.6 for the trend which can be used to predict future values. Whenever the predicted values are close to the actual values, this indicates the quality of the model used in forecasting.

Table 4. Actual value and the predicted values of CPI of Saudi Arabia

\begin{tabular}{ccccc}
\hline Time & $\begin{array}{c}\text { Actual } \\
\text { values of } \\
\text { CPI }\end{array}$ & Growth of trend $\left(R_{t}\right)$ & Level of the series $\left(V_{t}\right)$ & $\begin{array}{c}\text { Predicted } \\
\text { of CPI }\end{array}$ \\
\hline May 2019 & 97.5 & 0.00 & 97.47 & 97.5 \\
\hline June 2019 & 97.7 & 0.01 & 97.49 & 97.5 \\
\hline July 2019 & 98.0 & 0.04 & 97.55 & 97.6 \\
\hline August 2019 & 98.2 & 0.07 & 97.65 & 97.7 \\
\hline September 2019 & 98.4 & 0.11 & 97.79 & 97.9 \\
\hline October 2019 & 98.4 & 0.15 & 97.95 & 98.1 \\
\hline November 2019 & 98.3 & 0.16 & 98.12 & 98.3 \\
\hline December 2019 & 98.5 & 0.17 & 98.30 & 98.5 \\
\hline January 2020 & 98.4 & 0.17 & 98.46 & 98.6 \\
\hline February 2020 & 98.7 & 0.17 & 98.63 & 99.0 \\
\hline March 2020 & 98.8 & 0.17 & 98.81 & 99.1 \\
\hline April 2020 & 98.7 & 0.16 & 99.05 & 99.2 \\
\hline May 2020 & 98.5 & 0.12 & 99.07 & 99.1 \\
\hline June 2020 & 98.2 & 0.06 & 99.61 & \\
\hline July 2020 & 104.0 & 0.35 &
\end{tabular}

Originating Source: authors' own calculation based on data available at https://www.stats.gov.sa/en/394

Table 4 presents the actual observations of CPI and the predicted values for the same period, and it becomes clear that actual values are closer to the predicted values and indicates that the residuals have reached their lowest values. The line diagram depiction of actual values and predicted values explains the co-movability and trend of predicted values of CPI of Saudi Arabia. 


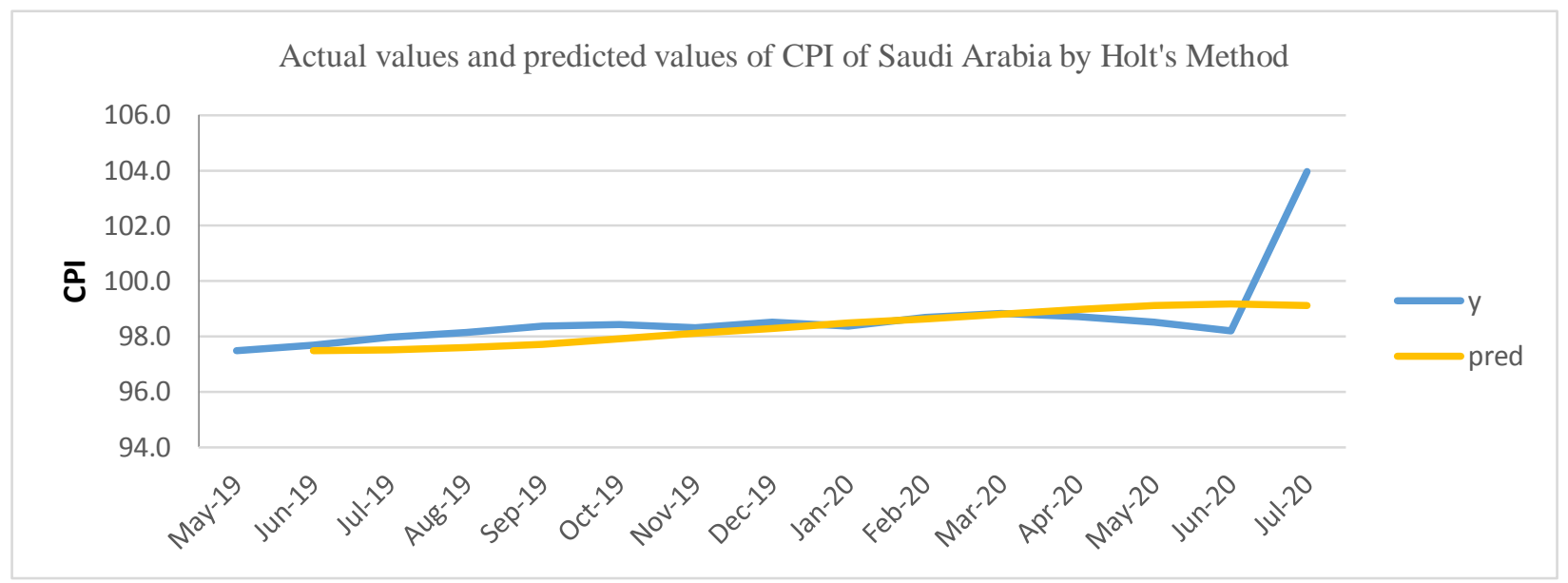

Figure 2. Actual values and the forecasted values of CPI of Saudi Arabia

Originating Source: Based on actual values given in Table 3.

Figure 2 shows the correspondence between the actual value curve of the price index and the predicted values for the same period, which indicates the quality of the model used in forecasting.

Table 5. Forecasted values of CPI for the next 11 months

\begin{tabular}{ccccccc}
\hline Time (Months) & Aug.,20 & Sep.,20 & Oct.,20 & Nov.,20 & Dec.,20 & Jan.,20 \\
\hline Forecasted CPI & 100 & 100.3 & 100.7 & 101 & 101.4 & 101.7 \\
\hline Time (Months) & Feb.,20 & Mar.,20 & Apr.,20 & May,20 & June,20 \\
\hline Forecasted CPI & 102.1 & 102.4 & 102.8 & 103.1 & 103.5 \\
\hline
\end{tabular}

Originating Source: authors' own calculation based on data available at https://www.stats.gov.sa/en/394

Table 5 presents the predicted values for the next eleven months which is completely inflated by the convergence of these values and indicates the general trend of these values.

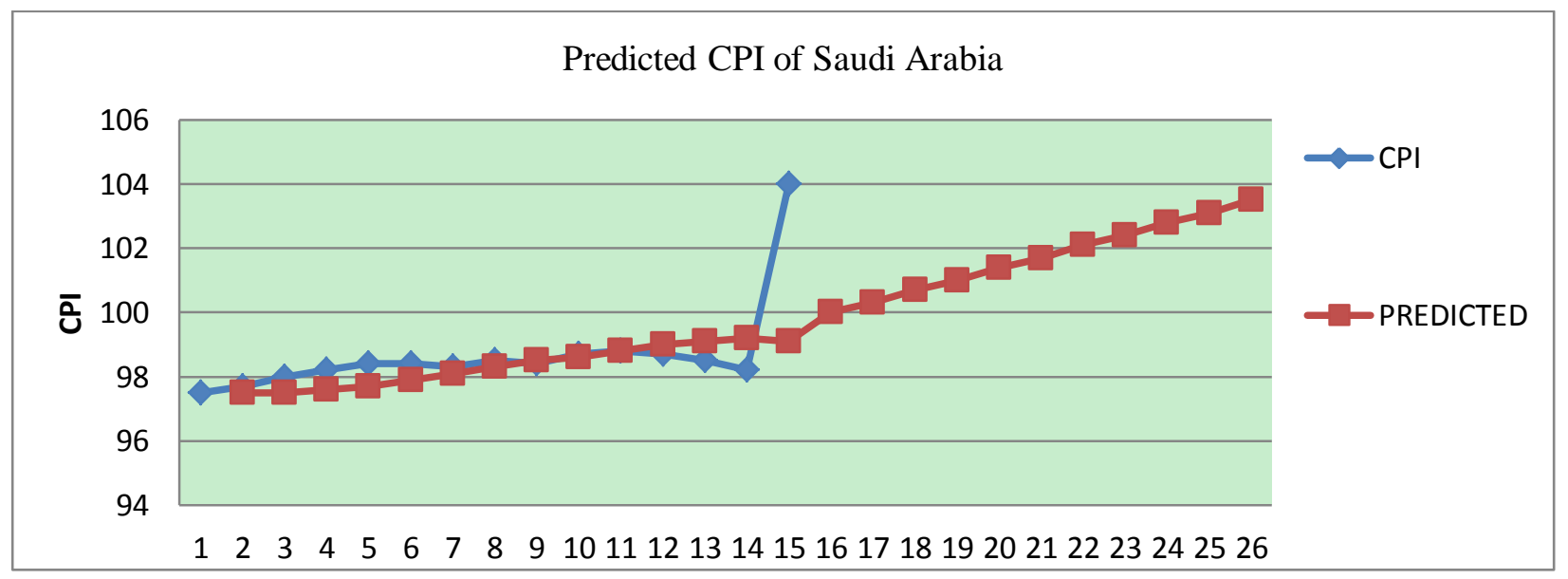

Figure 3. Predicted values of CPI of Saudi Arabia

Originating Source: Based on actual values of CPI (table 3) and forecasted values of CPI (Table 4). 
Figure 3 presents the predicted values for the next eleven months, and it is quite clear that the CPI of Saudi Arabia will tend to increase in a positive direction.

\section{Discussion}

Based on past studies it can be revealed that Akhter (2013) and Zhang et al. (2013) applied ARIMA and SARIMA model to forecast CPI accurately while Kharimah et al. (2015); Norbert et al. (2016); and Mustapa et al. (2019, June) and Jere et al. (2019) found the ARIMA and Multicointegration as the best model for forecasting the CPI and increasing prices comparatively. The Holt procedure generates a better forecast judging from the internal consistency of the smoothing model which does not overcorrect as reflected by low mean square error. There is also one to one correspondence between the actual value curve of the price index and the predicted values for the same period, which indicates the quality of the model used in forecasting. In this study, predicted values are very closer to the actual values and prove the accuracy of the prediction model. Recently, Ahmad, S.M., \& Nor, A.F.M. (2020), Xing, Y., Yue, J., Chen, C., Qin, Y., \& Hu, J. (2020), Syahrani, R., \& Astuti, I. F. (2020, April), Syahrani, R., \& Astuti, I. F. (2020, April), Tamber, A. J., \& Oladejo, O. M. (2020) applied Holt's linear model and found that suitable in forecasting the values. They observed that the double or triple exponential smoothing can give accurate results than the other forecasting approaches. Tirkeş, G., Güray, C., \& Çelebi, N. E. (2017), Zhu, Y., Zhao, Y., Zhang, J., Geng, N., \& Huang, D. (2019), Saputra, N. D., Aziz, A., \& Harjito, B. (2016, October), Vijayakumar, N., \& Vennila, S. (2016) applied Holt's linear model or Holt's hybrid model in forecasting demand, spring onion seed demand, crude oil prices, reservoir inflow and found appropriate as per the MAPE.

\section{Conclusion}

From all the above discussion and comparison with other prediction models, it can be concluded that Holt's linear approach is the most appropriate model to forecast the values in the short and long run. In Saudi Arabia, CPI is tending to increase in the next eleven months according to the prediction of Holt's linear model of forecasting. Generally, prediction models perform better for shorter periods than for longer periods, and as time passes the accuracy of the prediction decreases. However, in this attempt the period is moderate but the prediction may hold for the next few months because human behavior can not be predicted for the long term. This limitation is, however, inherent in all mathematical modeling relating to human consumption behavior. There is scope for further research to obtain the predicted values by applying the various hybrid models of Holt's linear approach.

\section{References}

Ahmad, S. M., \& Nor, A. F. M. (2020). Forecasting of universiti tun hussein onn Malaysia's electrical load by using Holt's linear trend \& holt winters techniques. ARPN Journal of Engineering and Applied Sciences, 15(12), 1398-1402.

Ahmar, A. S. G. S. A., Listyorini, T., Sugianto, C. A., Yuniningsih, Y., Rahim, R., \& Kurniasih, N. (2018, June). Implementation of the ARIMA ( $, \mathrm{d}, \mathrm{q}$ ) method to forecasting CPI Data using forecast package in R Software. In J. Phys. Conf. Ser, 1028(1), 012189.

Ahmar, A. S., Rahman, A., \& Mulbar, U. (2018). $\alpha$-Sutte Indicator: a new method for time series forecasting. In J. Phys. Conf. Ser, 1040(1), 012018.

Akhter, T. (2013). Short-term forecasting of inflation in Bangladesh with seasonal ARIMA processes. MPRA Paper, Munich University Library, Germany.

Box, G. E., Jenkins, G. M., \& Reinsel, G. C. (2011). Time series analysis: forecasting and control (Vol. 734). John Wiley \& Sons.

Bujang, M. A., Adnan, T. H., Supramaniam, P., Abd Hamid, A. M., \& Haniff, J. (2009). Prediction number of deaths by occurrence in Malaysia: a comparison between simple linear regression model and Holt's linear trend model. Statistics Malaysia-Journal of the Department of Statistics, Malaysia, 2, 25-37. https://doi.org/10.1088/1742-6596/995/1/012041

Chatfield, C. (2000). Time-series forecasting. CRC Press.

Hyndman, R. J., \& Athanasopoulos, G. (2018). Forecasting: principles and practice. OTexts.

Jere, S., \& Siyanga, M. (2016). Forecasting inflation rate of Zambia using Holt's exponential smoothing. Open Journal of Statistics, 6(2), 363-372.

Jere, S., Banda, A., Chilyabanyama, R., \& Moyo, E. (2019). Modeling Consumer Price Index in Zambia: A Comparative Study between Multicointegration and Arima Approach. Open Journal of Statistics, 9(2), 245-257.

Karmaker, C. L., Halder, P. K., \& Sarker, E. (2017). A study of time series model for predicting jute yarn demand: case study. Journal of Industrial Engineering, 1-8. https://doi.org/10.1155/2017/2061260 
Kharimah, F., Usman, M., Widiarti, W., \& Elfaki, F. A. M. (2015). Time series modeling and forecasting of the consumer price index Bandar Lampung. Science International Lahore, 27(5), 4619-4624.

Liu, L., \& Wu, L. (2020). Predicting housing prices in China based on modified Holt's exponential smoothing incorporating whale optimization algorithm. Socio-Economic Planning Sciences, 100916.

Mladenović, J., Lepojević, V., \& Janković-Milić, V. (2016). Modelling and prognosis of the export of the Republic of Serbia by using seasonal Holt-Winters and ARIMA method. Economic Themes, 54(2), 233-260.

Mustapa, F. H., \& Ismail, M. T. (2019, November). Modelling and forecasting S\&P 500 stock prices using hybrid Arima-Garch Model. In Journal of Physics: Conference Series, 1366(1), 1-13

Norbert, H., Wanjoya, A., \& Waititu, A. (2016). Modeling and forecasting consumer price index (Case of Rwanda). American Journal of Theoritical and Applied Statistics, 5, 101-107.

Razali, S. N. A. M., Rusiman, M. S., Zawawi, N. I., \& Arbin, N. (2017). Forecasting of water consumptions expenditure using Holt-Winter's and ARIMA. IOP Conf. Series: Journal of Physics: Conf. Series 995, 012041

Riofrio-Valarezo, J., Peluffo-Ordónez, D. H., \& Chang, O. (2020). Forecasting Consumer Price Index (CPI) of Ecuador: A comparative study of predictive models. International Journal on Advanced Science Engineering Information Technology, 10(3), 1078-1084.

Şahinli, M. A. (2020). Potato Price Forecasting with Holt-Winters and ARIMA Methods: A Case Study. American Journal of Potato Research, 97(4), 336-346.

Saputra, N. D., Aziz, A., \& Harjito, B. (2016, October). Parameter optimization of Brown's and Holt's double exponential smoothing using golden section method for predicting Indonesian Crude Oil Price (ICP). In 2016 3rd International Conference on Information Technology, Computer, and Electrical Engineering (ICITACEE), pp. 356-360.

Soni, R. S., \& Srikanth, D. (2017, May). Inventory forecasting model using genetic programming and Holt-Winter's exponential smoothing method. In 2017 2nd IEEE International Conference on Recent Trends in Electronics, Information \& Communication Technology (RTEICT) (pp. 2086-2091). https://doi.org/10.1109/RTEICT.2017.8256967

Syahrani, R., \& Astuti, I. F. (2020, April). Forecasting the number of airplane passengers uses the double and the triple exponential smoothing method. In Journal of Physics: Conference Series, 1524(1), 012051.

Tamber, A. J., \& Oladejo, O. M. (2020). Passengers' Traffic Forecast of the Nigeria Airports using the Holt-Winters Additive Model. Nigerian Annals of Pure and Applied Sciences, 3(2), 210-217.

Tirkeş, G., Güray, C., \& Çelebi, N. E. (2017). Demand Forecasting: A Comparison Between the Holt-Winters, Trend Analysis And Decomposition Models. Tehnicki vjesnik/Technical Gazette, 24.

Tratar, L. F., \& Strmčnik, E. (2016). The comparison of Holt-Winters method and Multiple regression method: A case study. Energy, 109, 266-276.

Vijayakumar, N., \& Vennila, S. (2016). A comparative analysis of forecasting reservoir inflow using ARMA model and Holt winters exponential smoothening technique. International Jour. of Innovation in Science and Mathematics, 4(2), 85-90.

Xing, Y., Yue, J., Chen, C., Qin, Y., \& Hu, J. (2020). A hybrid prediction model of landslide displacement with risk-averse adaptation. Computers \& Geosciences, 104527.

Yang, Y. M., Yu, H., \& Sun, Z. (2017, April). Aircraft failure rate forecasting method based on Holt-Winters seasonal model. In 2017 IEEE 2nd International Conference on Cloud Computing and Big Data Analysis (ICCCBDA), 520-524. IEEE.

Zhang, F. W., Che, W. G., Xu, B. B., \& Xu, J. Z. (2013). The Research of ARMA Model in CPI Time Series. In Applied Mechanics and Materials, 347, 3099-3103. Trans Tech Publications Ltd.

Zhu, Y., Zhao, Y., Zhang, J., Geng, N., \& Huang, D. (2019). Spring onion seed demand forecasting using a hybrid Holt-Winters and support vector machine model. PloS one, 14(7), e0219889.

\section{Copyrights}

Copyright for this article is retained by the author(s), with first publication rights granted to the journal.

This is an open-access article distributed under the terms and conditions of the Creative Commons Attribution license (http://creativecommons.org/licenses/by/4.0/). 